\title{
Ausencia y representación, mirada y poder: la imagen que no vimos de Bin Laden
}

\author{
Fernando REDONDO NEIRA \\ fernando.redondo@usc.es \\ Universidad de Santiago de Compostela
}

Recibido: 03/07/2012

Aceptado: 28/09/2012

\begin{abstract}
Resumen
La foto de Barak Obama y su grupo de colaboradores, atentos todos a una pantalla que ofrecía información sobre la operación que desembocó en la muerte de Bin Laden, constituye hoy el referente visual que informa de aquel hecho trascendental. Ante la ausencia de la imagen del cadáver del líder terrorista, ésta otra ofrece una rica configuración significante que, por medio de un relevante juego de espejos, pone en conexión personajes, acciones o lugares que, de un modo u otro, intervienen en el acontecimiento noticioso. Las miradas hacia un fuera de campo que se niega al espectador ponen de relieve una clara manifestación de poder y de dominio sobre el material informativo.
\end{abstract}

Palabras clave: imagen, ausencia, representación, mirada, poder

\section{Absence and representation, look and power: the Bin Laden's picture we haven't seen}

\begin{abstract}
The picture of Barak Obama and his group of collaborators, all watching to a screen that provided information on the operation that led to the death of Bin Laden, represents nowadays the visual reference that reports that momentous event. In view of the absence of the image of the terrorist leader's corps, this one offers a rich signifying configuration that, by means of a relevant set of mirrors, connects characters, actions or places that, in one way or another, are involved in the big event. The looks toward the screen hidden to the audience highlight a clear manifestation of power and control over the information material.
\end{abstract}

Keywords: image, absence, representation, look, power

\section{Referencia normalizada}

REDONDO NEIRA, Fernando (2012): “Ausencia y representación, mirada y poder: la imagen que no vimos de Bin Laden". Estudios sobre el mensaje periodístico. Vol. 18, núm. especial noviembre, págs.: 763-770. Madrid, Servicio de Publicaciones de la Universidad Complutense.

Sumario: 1. Introducción. 2. Foto de grupo. 3. Fuera de campo activado. 4. El tiempo de la espera. 5. Referencias bibliográficas.

\section{Introducción}

En contraste con la opulencia visual que caracteriza el actual universo de imágenes, de la operación militar que derivó en la muerte (o ejecución) de Osama Bin Laden no ha quedado constancia gráfica en lo considerado más relevante: la foto del cadáver del terrorista. Sabemos que tal foto existe, pues de ella han informado los medios, pero nadie la ha visto. Lo que ha quedado como icono para reconocer visualmente aquel acontecimiento es la célebre imagen de Barak Obama y su grupo de colaboradores, atentos todos a una pantalla que ofrecía información sobre la operación desencadenada en Pakistán contra el líder de Al Qaeda. Nos proponemos aquí comprender los mecanismos de producción de sentido activados en este concreto texto visual, junto con un 
breve análisis de la relación que mantiene con otras imágenes vinculadas al suceso. Siguiendo, en consecuencia, las indicaciones contenidas en el fundamental libro de Javier Marzal (2007: 167), el análisis procurará, sobre todo, "desarrollar indagaciones sobre nuestra propia relación con las formas de representación de la realidad y, en definitiva, con la propia realidad". Dicho en palabras de Josep María Catalá (2008: 46), vamos a pedirle a la imagen que nos cuente sus secretos, aquellos que nadie ha buscado manifiestamente cuando se confeccionaba ni nadie esperaba realmente recibir, pero que están en ella. En definitiva, se propone un trayecto analítico que recorra, siquiera sumariamente pero en lo fundamental, los niveles contextual, morfológico, compositivo y enunciativo.

Mariona Visa y Joana Soto (2012: 30) analizaron en su momento las fotos de portada en los cinco diarios españoles de mayor tirada que daban cuenta de la muerte de Bin Laden. Concluían allí que la ausencia de la foto en cuestión había permitido evitar la imagen de impacto, cargada de morbo y vacía de información. Sí se difundieron, no obstante, las fotos de tres cuerpos cubiertos de sangre, tomadas al parecer por un funcionario pakistaní en la casa de Abbottabad donde se refugiaba el célebre terrorista, dadas a conocer por la agencia Reuters. En la red aún pueden verse, además, vídeos grabados en las horas posteriores al asalto, que sin duda son obra, según las informaciones de prensa, de funcionarios pakistaníes que entraron en la casa cuando todo había acabado. También están disponibles, en plataformas como youtube, otras piezas incautadas por las tropas norteamericanas, como un vídeo que muestra a Bin Laden ensayando uno de sus característicos mensajes o viéndose a sí mismo en la televisión, en una insólita imagen cotidiana que es también un llamativo juego de espejos: el protagonista se nos muestra a uno y a otro lado del dispositivo audiovisual, como emisor y como receptor de su propia emisión, en una pantalla, por cierto, en la que también se ve a Barak Obama, lo que complejiza aún más el dispositivo especular. Son fotos e imágenes en movimiento que se acercan, casi hasta rozarla, a esa foto que no hemos llegado a ver y que fue reclamada por los más escépticos en relación con la muerte del líder terrorista. La que ocupa ese lugar central a la hora de construir visualmente aquel acontecimiento es esta otra foto, como también han destacado las autoras antes citadas, de Obama y su grupo de asesores del área de Seguridad.

\section{Foto de grupo}

La foto en cuestión es obra de Pete Souza, fotógrafo jefe de la Casa Blanca. Ocupó, por supuesto, portadas en medios de todo el mundo y fue objeto de todo tipo de comentarios y análisis que incidieron, principalmente, en la mirada fija de Barak Obama o en el gesto asustado de Hillary Clinton. Está tomada en la Situation Room de la Casa Blanca, la estancia donde se tratan los asuntos de seguridad y de terrorismo y forma parte de una serie de cuatro instantáneas. En una de ellas, el presidente, en plano medio señala a cámara con el dedo. En realidad sabemos que señalaa la pantalla que tiene ante él mientras habla con uno de sus asesores. En otra, un primer plano lateral de Obama, con el puño cerrado apoyado sobre el mentón, recoge la gravedad del momento. La tercera de las fotos formaría una suerte de díptico con la imagen principal, pues, a modo de contraplano, nos es dado a ver, al fondo, la pantalla a la que los per- 
sonajes retratados dirigían su atención. Como tantas otras fotos del día a día del presidente de los Estados Unidos, la serie completa puede verse en la cuenta que la Casa Blanca mantiene en la red social Flickr.

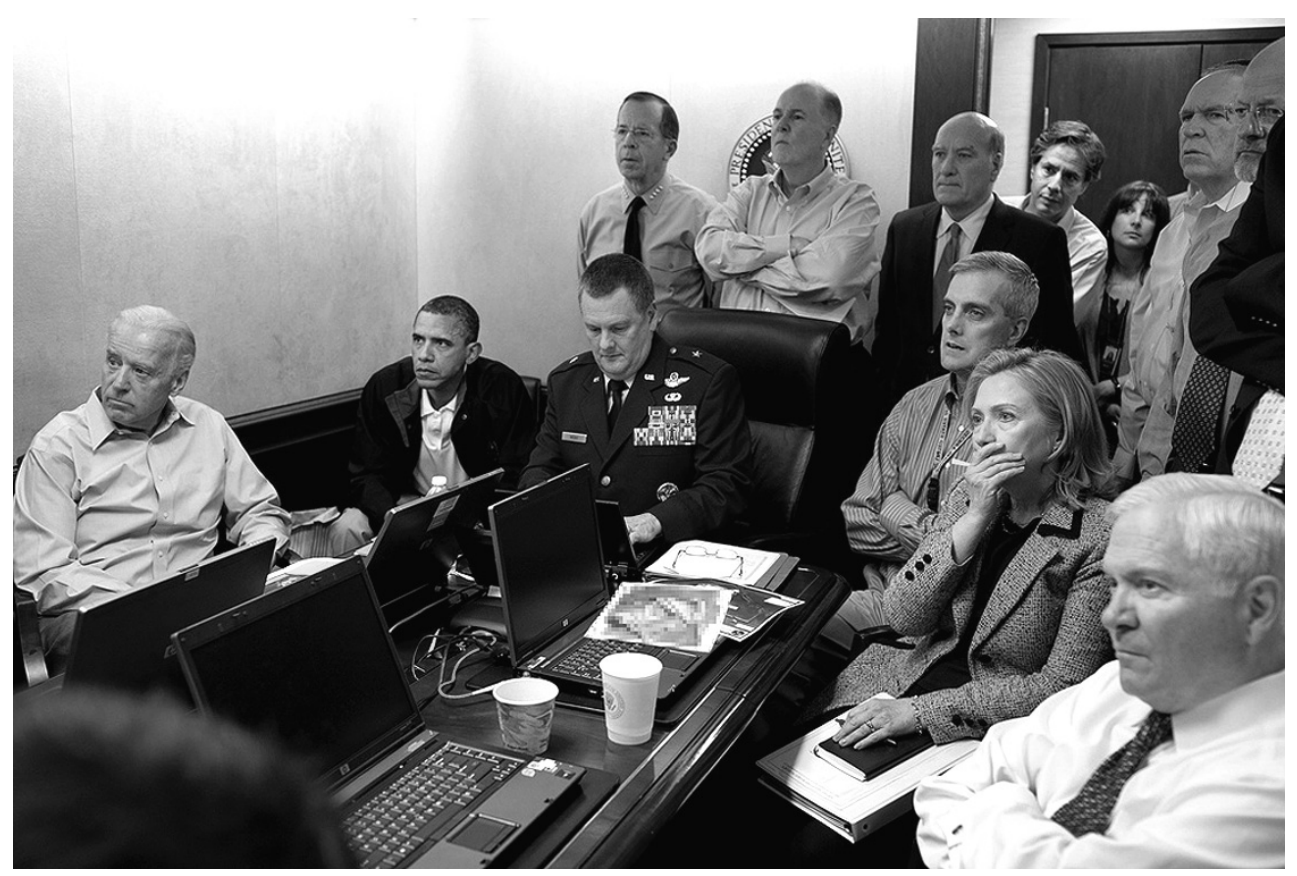

Barak Obama y su grupo de colaboradores en la Situation Room de la Casa Blanca

Foto tomada de: http://elimparcialnews.com/2011/05/07/614/

Estas otras imágenes de las que se hace acompañar la que es objeto de nuestro análisis nos conducen a una pertinente reflexión de Josep María Catalá sobre el régimen visual contemporáneo. Afirma que las imágenes difícilmente se perciben aisladas y que nuestra mirada ha entrado en un régimen perceptivo tal que se encarga de agrupar unas con otras (Catalá, 2005: 46). Pero además, en este caso, será la foto escamoteada, la primera imagen con la que ésta se relaciona, pues el espectador no puede desprenderse del conocimiento de su existencia, como tampoco puede obviar otras muchas imágenes que van agrupándose entre sí, estableciendo una mayor o menor cercanía entre ellas, en un encadenamiento en red por hechos diversos que se van sucediendo y que nos llevaría, por establecer una referencia, a los acontecimientos del 11-S.

Asesores en temas de seguridad y terrorismo, altos jefes militares, Secretaria de Estado y Secretario de Defensa, Vicepresidente y Presidente conforman esta foto de grupo en torno a la mesa de la Situation Room. Han sido convocados para seguir en tiempo real la operación militar diseñada para localizar y detener (o directamente disparar a matar) a Bin Laden. Se ha esperado casi diez años para llegar a este momento, por eso esta foto se complementa con aquella otra en la que un avión se dirige hacia una de las torres gemelas del World Trade Center de Nueva York, por elegir una de las 
muchas imágenes que ilustraron los hechos de 2001. Todos ellos miran atentamente a un punto fijo en el fuera de campo. Nos han dicho que miran a una pantalla. También se ha dicho que asisten en directo a la operación del comando que acabará matando al terrorista saudí; pero en realidad atienden al relato de los hechos que realiza Leon Panetta, director general de la CIA desde Langley, Virginia. Si debemos atender a lo que publicaron los periódicos en su día, la información que recibe Obama pasa, por tanto, por este filtro. Panetta sería aquí la encarnación de un verdadero gatekeeper, ocupando así una posición de predominio sobre el mismísimo presidente. Si atendemos ahora a lo que la propia foto ofrece, comprobaremos que al lado de Obama está sentado Marshall B. Brad Web, adjunto al Comandante en Jefe de la unidad de la que dependen los Navy Seals (cuerpos de élite para operaciones especiales del ejército norteamericano), de lo que cabe deducir que por este importante cargo militar pasaba también todo lo que había que saber sobre la operación en marcha.

Foto de grupo en torno a una mesa: esta podría ser una primera y sencilla descripción de la imagen. La percepción se organiza en función de dos puntos de interés, cuya relevancia no es en absoluto de carácter exclusivamente visual, sino que tiene que ver con lo que el sujeto de la percepción sabe de antemano. Se trata de los dos personajes cuyos rostros son universalmente reconocidos: el presidente Barak Obama, en el lado izquierdo de la mesa, y la Secretaria de Estado, Hillary Clinton, que se destaca con su comentado gesto en el lado derecho. Podríamos reconocer, además, a quien se sitúa a la derecha de Obama, el vicepresidente Joe Biden. Como lo ya sabido también interviene en la lectura de la imagen, cabe esperar que el espectador dirigirá su atención a través de esa línea imaginaria que une ambos puntos.

En este nivel morfológico del análisis de la imagen, los sujetos citados, junto con el jefe militar, además de Robert Gates, Secretario de Defensa y Denis McDonough, adjunto al asesor de Seguridad Nacional, ocupan el primer término de la composición, conformando así un primer nivel jerárquico. A continuación, de pie, se sitúan otros asesores de menor rango. Nótese que se han colocado no para componer una imagen, sino para contemplar otra. El relativo aislamiento de presidente y vicepresidente, en el lado izquierdo, establece una primera relación de equilibrio, en virtud del peso visual y la jerarquía que estos ostentan, al contraponerse a la masa de personas ubicadas en la otra mitad del encuadre.

Hay que considerar, finalmente, un elemento fundamental, de mayor alcance si cabe y principal factor, a nuestro juicio, de estructuración del espacio representado: la pantalla situada fuera de campo que, por las informaciones externas al propio texto fotográfico, sabemos que ocupa ese lugar excluido de la representación hacia la que todos dirigen su mirada. Según la teoría relativa a la representación del espacio en perspectiva, en el lado opuesto, al fondo de la imagen, se sitúa el punto de fuga, en esa apertura hacia otro exterior que se extiende más allá de la puerta abierta de la Situation Room. Esa puerta marca, entonces, la posibilidad de acceso al ámbito de poder que representa esta estancia, una puerta que alguno de los sujetos fotografiados tan sólo traspasa parcialmente. Esa puerta permite, además, el acceso a un segundo nivel de poder, que no es otro que la posibilidad de conocer de primera mano el desarrollo de los acontecimientos en Pakistán, sea lo que fuere lo que aquella pantalla mostrara, 
justo lo que se nos niega a los espectadores, que no podemos ver lo que ellos ven como tampoco hemos visto la foto de Bin Laden muerto.

\section{Fuera de campo activado}

Estas miradas fuera de campo, que apuntan hacia lo excluido, activan, por tanto, una fuerza centrípeta que arrastra consigo la propia mirada del espectador, movilizando así una cierta manifestación de la pulsión escópica: este deseo de ver lo que ellos ven, de conocer la razón de esos gestos de profunda seriedad y tensión, deseo que el gesto de Hillary Clinton no hace sino incrementar. Se articula aquí entonces una sugerente estructura en abismo, un mecanismo de visión en cadena en la que cada mirada exige otra. El espectador les ve viendo algo. Nuestra mirada rebota en la suya e intenta, en vano, reconducir su trayectoria hacia ese espacio excluido que atrae su atención. El juego de encadenar miradas en sucesión no se detiene aquí porque, como hemos adelantado, estos sujetos están contemplando una escena no muy diferente, probablemente, de la que ellos mismos conforman. En otro lugar (en Virginia), otra sala, otros personajes (Leon Panetta, entre ellos), informan de lo que ocurre en un tercer lugar (Abottabbad, Pakistán) y, estos sí, parece que tienen acceso visual a la acción desencandenante de todo el dispositivo, a la imagen escamoteada a todos los demás. El sujeto espectador ostenta, así, una mirada ciega respecto de lo fundamental pero conocedora de que eso que se le oculta existe en un lugar inaccesible para ella. Desconocemos lo que han podido llegar a ver los ocupantes de la Situation Room y si ha habido algún tipo de retorno en esta disposición en abismo, si esta estructura en cadena se ha roto, por tanto, en algún punto de la conexión establecida entre Washington, Virginia y Abottabbad.

Solo uno de los personaje que conforman el grupo fotografiado no está mirando a la pantalla. Mantiene la vista baja, pendiente de su propia pantalla de ordenador. Se trata del ya citado Marshall B. Brad Web. Con su uniforme de alto jefe militar, con la pechera cuajada de medallas, ocupa la silla presidencial en la cabecera de la mesa, que el propio Obama parece haberle cedido. Tanto esta ubicación privilegiada como su posición en el grupo de colabordores del presidente y su actitud ante lo que sabemos que está ocurriendo, revelan el importante papel que aquí desempeña. La configuración del discurso visual, su organización y disposición enunciativas derivadas de la composición y de la dirección de las miradas revelan que si Obama le ha cedidio su lugar, estaríamos ante una acción que ha obligado a trasladar el mando desde el ámbito político al militar. En el fondo, aquello a lo que la imagen remite, desde la inmediatez de lo mostrado, es a la idea de poder (de la que participa la presencia del escudo presidencial). Recordemos que aquí están representadas áreas tales como los asuntos exteriores, la defensa, la seguridad o la lucha antiterrorista. En todas ellas se hace necesaria la cooperación entre lo político y lo militar, y, en casos como éste, lo segundo se impone a lo primero.

El ejercicio del poder se manifiesta en imágenes como ésta, que ocultan más de lo que muestran. Mostrándose ellos impiden que se nos muestre lo que no quieren que veamos al mismo tiempo que les vemos contemplando la imagen prohibida. Remiten a lo que ya Michel Foucault ha definido como "lo decible", o en este caso lo "visible", 
aquello que la sociedad deja ver e instituye que se ha de ver; el poder en tanto que capacidad de control por medio del discurso. Foucault lo explicaba así: "[...] en toda sociedad la producción del discurso es a la vez controlada, organizada y redistribuida por cierto número de procedimientos que tienen por función conjurar los poderes y los peligros, domeñar el acontecimiento, esquivar en él la pesada y desagradable materialidad". (Foucault, 1983: 11)

Ampliando el campo hacia los hechos noticiosos, ésta es también una prueba de cómo se dosifica la información y se da a conocer de tal modo que no produzca efectos no deseados. Como ha destacado Miquel Rodrigo Alsina (2005: 132), siguiendo a Pierre Nora, el acontecimiento, como la verdad, es revolucionario, y los poderes instituidos tienden a reducir su poder corrosivo para así evitar la ruptura del equilibrio, fundamento de dichos poderes. La noticia de la muerte de Bin Laden no sería ajena a este planteamiento. Se trataría, entonces, de poner punto final a esos vídeos-manifiesto cargados de amenazas y soflamas que tanta popularidad añadida aportaron al líder radical islámico y a través de los cuales trató de evidenciar su permanente presencia. Negando ahora su imagen se buscaría conjurar esta amenaza.

\section{El tiempo de la espera}

El estudio del corte del continuo temporal al que obliga todo examen del tratamiento del tiempo en la imagen fotográfica conduce a abordar dicha interrupción como fuertemente condicionada por un "después" de lo que ocurre. Los gestos de fija atención, la seriedad dominante, el silencio que se adivina y, principalmente, la concentración de las miradas (todas menos una) en un mismo punto, construyen este ambiente de espera. Se deduce una tensa expectación ante algo que va a ocurrir o que está ocurriendo ya. Lo que ocurre, sea lo que sea, ocurre ahí afuera. Aquí, la quietud, la espera, la atenta observación. Allí, la acción, el devenir, el fuera de campo donde todo acontece y que contemplamos desde aquí (o que contemplamos a través de lo que contemplan otros en otro lugar). La limitación del medio fotográfico para representar el devenir temporal se supera en este caso a través de esta remisión al fuera de campo designado por la mirada unánime de los personajes fotografiados, a ese exterior donde sabemos que algo importante está ocurriendo; que sabemos también, no lo olvidemos, por el relato noticioso de los hechos, con sus datos, concreciones, antecedentes o nombres de los protagonistas que cumplen, entre todos, la barthesiana función de anclaje. Pero lo anterior no anula el proverbial sincretismo de la imagen fotográfica, capaz de recoger cuanto de significativo tiene el hecho de referencia con el añadido de transmitir, con la inmediatez propia del texto visual, la expectación reflejada en los rostros o la inquietud impresa en el gesto de Hillary Clinton. Se entiende así el concepto de acto fotográfico que Philippe Dubois (1986: 146) desarrolla en su célebre libro: la noción de instantánea no excluye una relación con la duración ni con la existencia de una gran movilidad interior.

Desde la teoría de la percepción, el suspense a que nos somete el propio acto de la visión, el deseo y la curiosidad, son analizados por Ernest H. Gombrich (2002: 188), para quien la expectativa, en el arte como en la vida, modela lo que vemos y tiene un peso mayor que el conocimiento conceptual. Esas miradas (atentas, inquietas, expec- 
tantes) de Obama y sus colaboradores y ese gesto de Hillary Clinton conforman una atracción visual que avanza más allá de lo reflexivo o de un cierto ejercicio racional del poder para acceder al ámbito donde confluyen la belleza y el horror, como tan lúcidamente nos han explicado pensadores como Eugenio Trías, quien afirma que el sentimiento de lo sublime se alumbra en plena ambigüedad entre dolor y placer, que el objeto que produce dicho sentimiento debería, en teoría, despertar dolor en el sujeto y que, para poder ser gozado, este objeto debe ser contemplado a distancia, lo cual, esto último, resulta especialmente pertinente tratándose de un fenómeno de la comunicación visual (Trías, 2000: 137).

Sin abandonar aún la dimensión temporal de esta imagen, cabe advertir también del conocimiento de la existencia de otras fotos, ya citadas, con las cuales ésta se relaciona a modo de secuencia que sugiere una cierta idea de duración del hecho en cuestión. No es posible abordar por sí sola esta imagen, ya que se prolonga en otras, a las cuales sigue o precede. Si bien intuititivamente pudiéramos colocar por orden cada una de estas fotos, no tendríamos la certeza de que fuera el orden verdadero. Las fotos de la Situation Room dadas a conocer a través de la red Flickr, y luego por medio de la prensa internacional, junto con las imágenes de la casa de Abotabbad que conocimos, y que se corresponden con un antes y un después del asalto (poco importa ahora que sean los consabidos vídeos vertidos a Youtube o las fotos de los cuerpos de quienes acompañaban a Bin Laden), contribuyen a crear una forma posible de relato completo. La foto aquí analizada se constituye en un eslabón más del relato noticioso, que dirige, además, dicho relato hacia un punto ciego de la historia, al que designa sin mostrar, que apunta (las propias miradas apuntan, señalan) hacia la imagen que debería figurar como desenlace del relato.

La mirada actúa aquí también como factor determinante en la articulación entre los niveles compositivo y enunciativo del análisis, como transición en virtud de su relevante participación en la creación de sentido. Del análisis del punto de vista físico deducimos que la fotografía ha sido tomada a la altura de los ojos de los personajes situados en el segundo término de la composición y que, en atención a sus miradas, el fotógrafo se encontraba a la derecha de la pantalla a la que todos miran. No se constata propósito alguno de hacer visibles las marcas de una intencionalidad subjetiva. La instancia enunciativa parece sumergirse en la propia escena fotografiada, incorporada así al grupo reunido en torno a una mesa y a una pantalla. Es la paradoja de estar tanto más oculta cuanto más incorporada al espacio de la representación, pues no desvela la existencia de un ámbito que pueda considerar propio. El punto de vista que comparten el sujeto de la enunciación y el sujeto observador promueven un alto grado de acercamiento a lo mostrado, de simulacro de presencia, de inmediatez que deviene de esta ilusión de estar donde se desarrollan los acontecimientos.

Fuera de campo y mirada, interactúan entre sí, remiten el uno al otro. Aquella decisiva intervención del fuera de campo no hace sino incidir en la presencia de lo ausente. Se ha preferido mantener en la invisibilidad esa imagen de impacto, esquivándose así la satisfacción de la pulsión primaria del morbo escópico para ofrecer, en su lugar, esta otra representación, como si se hubiera obligado al espectador a girar la mirada hacia aquellos que ven lo que a nosostros se nos impide ver. Escamoteando así la cru- 
deza que se le supone a estas imágenes, sería pertinente atender a la reflexión de JeanLouis Comolli (2007: 78), quien se ha preguntado si la representación de la violencia es o no una violencia ejercida sobre la representación y si gozar del espectáculo del desamparo del cuerpo del otro deja indemne al espectador.

Finalmente, el mismo poder que ha decidido no mostrar la fotografía en cuestión, se nos impone como visión obligada, tal como ya hemos desarrollado en nuestro análisis. Con todo, aún quedaría en el fuera de campo otro fundamental agente de poder: el director de la CIA, Leon Panetta.

\section{Referencias bibliográficas}

CATALÁ DOMENECH, Josep Maria (2005): La imagen compleja. La fenomenología de las imágenes en la cultura visual. Barcelona, Universidad Autónoma.

CATALÁ DOMENECH, Josep Maria (2008): Las formas de lo real: introducción a los estudios visuales. Barcelona, UOC.

COMOLLI, Jean-Louis (2007): Ver y poder. La inocencia perdida: cine, televisión, ficción, documental. Buenos Aires, Nueva Librería.

DUBOIS, Philippe (1986): El acto fotográfico. De la representación a la recepción. Barcelona, Paidós.

FOUCAULT, Michel (1983): El orden del discurso. Barcelona, Tusquets Editores.

GOMBRICH, Ernest H. (2002): Arte e ilusión: estudio sobre la psicología de la representación pictórica. Madrid, Debate.

MARZAL FELICI, Javier (2007): Cómo se lee una fotografía. Interpretaciones de la mirada. Madrid, Cátedra.

RODRIGO ALSINA, Miquel (2005): La construcción de la noticia. Barcelona, Paidós.

TRÍAS, Eugenio (2000): Lo bello y lo siniestro. Barcelona, Planeta.

VISA BARBOSA, Mariona y SOTO MEROLA, Joana (2012): "La muerte de Bin Laden en fotografías de portada de la prensa española ¿Sin cuerpo no hay imagen icónica?", Cuadernos de Información, $\mathrm{n}^{\circ}$ 30. Santiago de Chile. Pontificia Universidad Católica de Chile, pp. 139-150.

\section{Fernando REDONDO NEIRA}

fernando.redondo@usc.es

Profesor Contratado Doctor

Facultad de Ciencias de la Comunicación

Universidad de Santiago de Compostela 